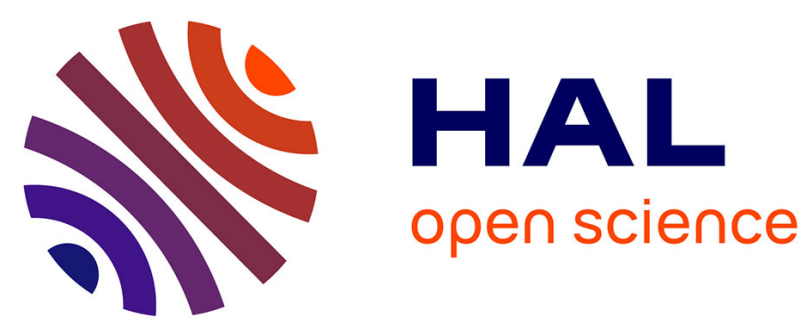

\title{
REQUIREMENT AND USE FOR REMOTE TEACHING OF DISCRETE EVENTS SYSTEMS
}

Pascale Marangé, François Gellot, Bernard Riera

\section{To cite this version:}

Pascale Marangé, François Gellot, Bernard Riera. REQUIREMENT AND USE FOR REMOTE TEACHING OF DISCRETE EVENTS SYSTEMS. 7th IFAC Symposium on Advances in Control Education (ACE'06), Jun 2006, Madrid, Spain. pp.CD. hal-00385496

\section{HAL Id: hal-00385496 https://hal.science/hal-00385496}

Submitted on 19 May 2009

HAL is a multi-disciplinary open access archive for the deposit and dissemination of scientific research documents, whether they are published or not. The documents may come from teaching and research institutions in France or abroad, or from public or private research centers.
L'archive ouverte pluridisciplinaire HAL, est destinée au dépôt et à la diffusion de documents scientifiques de niveau recherche, publiés ou non, émanant des établissements d'enseignement et de recherche français ou étrangers, des laboratoires publics ou privés. 


\title{
REQUIREMENT AND USE FOR REMOTE TEACHING OF DISCRETE EVENTS SYSTEMS
}

\author{
Pascale MARANGE ${ }^{1}$, François GELLOT ${ }^{1}$, Jean Paul CHEMLA ${ }^{2}$, Bernard RIERA ${ }^{1}$ \\ ${ }^{1}$ UFR Sciences Exactes et Naturelles, \\ CReSTIC-LAM, Université de Reims Champagne Ardenne, \\ Moulin de la Housse, BP 1039 - 51687 Reims, \\ pascale.marange@univ-reims.fr,francois.gellot@univ-reims.fr,bernard.riera@univ-reims.fr \\ ${ }^{2}$ Université François Rabelais de Tours, LUSSI FRE 2448, \\ Polytech'Tours, Département Productique, 7 av Marcel Dassault, 37000 Tours, \\ jean-paul.chemla@univ-tours.fr,
}

\begin{abstract}
Today, Internet makes possible remote access to PLC (Programmable Logic Controllers) remote maintenance, monitoring, supervision and follow-up of plants. In this article, we are interested in the possibilities that Internet offers for the D.E.S (Discrete Events System) teaching. The concept of distributed practical work room is proposed in order to facilitate the technical know-how transmission. The idea consists for students, on the one hand to use a real PLC and specialized software via Internet and on the other hand, to check their controller program by the mean of a plant simulation. In addition, the controller program verification problem is proposed. Indeed, as well within the framework of the real as simulated plant use, it is necessary to develop controller verification tools able to cooperate with the teacher and students and having explanatory capacities.
\end{abstract}

Keywords: Controller verification, Discrete Events System, remote use, plant simulation.

\section{INTRODUCTION}

Nowadays, the use of Communication and Information Technologies is a reality in the automation field. Indeed, one can find a massive use of the Ethernet network, as well on the level of the inputs/outputs (sensors and actuators), as in the communication between Programmable Logic Controllers (PLC). The use of protocol TCP-IP, integration of Web server in the PLC able to send Email or to connect to data bases like Oracle, Sql server or My SQL are classical applications. Thus, remote (or distant) access to the controller part via Internet has become a reality, allowing for example PLC programming, supervisory control and plant maintenance.

This paper deals with different possibilities provided by Internet for the "practical" teaching of Discrete Events System (D.E.S) theory. The idea that we have developed is to give the possibility to students to use, in a remote way, some professional materials (Control part and plant) and software packages which they cannot lay out by them. In the field of the automatic control of continuous processes, use of virtual and/or remote laboratories for teaching is well known. We can quote for example Metzger's work (Metzger, 2004) which uses Internet to reach virtual control devices for the teaching of the distributed control devices, or those from Riera (Riera and al., 1999) which developed plant simulations called "virtual models" used before practical work. In the field of remote use of real system in feed-back control, we note work of (Lunt and al., 2000), (Lottin and Morteau, 2005), (Hsieh, 2004), (Tauvel and Flety, 2005)

On the other hand, only few papers concern the D.E.S teaching and the use of real or simulated control/command systems (control part) and manufacturing systems (plant) in a local or remote way.

The first part of the article deals with the specificities of the D.E.S teaching, which depends on the concerned public and the objectives (discovery, initiation, specialization). The discovery can be illustrated by the mean of simulation. However, when it is necessary to transmit a know-how (initiation or specialization), the use of PLC and specialized software packages is important. That requires expensive classrooms. A possible solution is to simulate plant. However, within the framework of the higher studies, it is necessary to go further and to set up projects on real plant, that make possible to approach the various facets of the automatisms. An example of original project is presented in this paper. Supervision of practical work-projects arises 
problems to the teacher who must have many technical competences and to be sure that the suggested control program proposed by student respects safety requirements.

The second part of the article shows how D.E.S teaching activities can use Internet at different levels, from discovery to specialization, to supply to students, PLC connected to real or simulated plant. The case of the self-training and the case of the supervised practical courses will be approached. The concept of distributed practical work room is introduced and different architectures for the plant simulation are suggested.

The last part of the paper deals with the problem of controller checking. Indeed, as well in self-training as the real plant, it seems to us important to design software tools able to detect several programming errors or failures and supplying support and explanations either to the teacher or the students. Thus, the use of Internet for the D.E.S teaching applications has led us to study interesting research model checking problems.

\section{THE D.E.S TEACHING: FROM THE THEORY TO THE PRACTICE}

The teaching of the automatic in the broad sense requires the transfer of knowing and know-how to learners. In the case of the D.E.S teaching, the knowledge is characterized by the study of states automata, combinatory and sequential logics, Statecharts, Petri nets, Grafcet, SFC ... The level of knowledge is linked to the teaching level varying from discovery to specialization. Know-how concerns for instance the use and the programming of PLC by means of software respecting standard like IEC 1131.3. The acquisition of this technical know-how requires practical work in specialized and expensive rooms including PLC and simplified manufacturing systems which are a replica on a reduced scale of a real system found in the industry. These rooms moreover essential, must be maintained by specialized personnel and are not generally in free access for security reasons. An alternative is to use some plant simulation models. That is not without arising pedagogical and technical questions.

\subsection{Real or simulated plant}

The real and simulated plant (Riera and al., 2004) allows the student to test its own designed controller using industrial hardware like PLC and programming software that he or she is supposed to find in his or her professional life (cf. figure 1).

We thus find the two fundamental aspects of the formation:

- Acquisition of a knowledge (control theory of the D.E.S),

- Acquisition of a know-how (applied with hardware and application software).

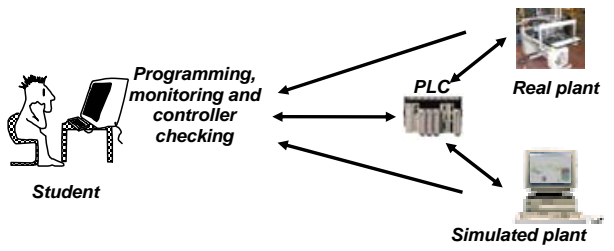

Figure 1. Use of real or simulated plant

Real and simulated plants have advantages and disadvantages which are now detailed

\subsubsection{Use of real plant}

It is obvious that real plant has advantages from a teaching point of view. It look likes a physical reproduction of an industrial system, generally designed with industrial components. Additional security measures were added to avoid the accidents. Hence, students use them as they would do it in their professional life. On the other hand, its cost is often expensive and it requires maintenance by qualified personnel. It is also subjected to hard test by learners who make errors of design in the control. That involves failures which make plant unavailable during a certain time. The practical work with real plant requires for the teachers a lot of experiences, competences and time. It is important to note that teacher must generally manage about fifteen students simultaneously organized by pair. The development stations are not always located close to plant. While several students design or modify their control program, others are testing it on plant. Hence, at the time of the start-up, the teacher must supervise the plant; make sure that there are no error in the controller and no failure of sensors and actuators, while managing the other students learning!

When PLC and real plant are used, firstly controller must be validated at least from the point of view of security before being implemented in the PLC. Secondly, some supervisory tools to monitor and to detect dysfunctions of plant must be placed at the disposal of the teacher to allow him "to keep eyes" on the installation. We are interested in designing tools checking PLC program quality.

The simulation use makes it possible to solve some of the mentioned problems but cannot replace completely a real plant.

\subsubsection{Use of simulated plant}

The main differences between a simulated plant (also called virtual model) and a traditional simulation are:

- A realistic rendering of the layout, the functions and the behaviour of the system,

- A respect of the system dynamics.

Simulation is a classical tool for control engineering. Very often the control and the system are simulated jointly. That involves comprehension problems for the students who are not able at the beginning of the learning process to distinguish them. The student handles a virtual model in the same way that the real one. Efficient HMI (Human Machine Interface) 
combined with sound rendering with the respect of dynamics must support the interactivity with the student, and improve the link between theory and practice. The virtual model can be used at different levels (course, tutorial, practical work, self-training, etc). The simulation of plant can be done either in PLC, or in a computer of the type PC. The Communication and Information Technologies by the mean of Ethernet and technologies as OPC (OLE for Process Control) make it possible to connect easily a plant simulation to PLC.

The use of real plant within the framework of the technical and technological formation is absolutely necessary. Today the teaching of the automation field also requires several courses about Communication and Information Technologies which are massively present in the world of the industrial data processing (Ethernet, Internet, OPC servers, HTML, Embedded Web server in the PLC, connection with database ...). Within the framework of specialized trainings, at the Reims University (France), we propose applied projects to work with and to implement the various "facets" of automation. In this case, experimental plants with several PLC are the most interesting from a teaching point of view, but also, as we have already seen, difficult to manage by the teacher.

One project carried out for the French science festival, is presented in the following part of the paper.

\section{5-YEAR-OLD CHILDREN TO THE HELP OF SICK ANIMALS!}

The University of Reims Champagne Ardenne has an automated machine called "Productis" (Schneider electric, 2001), allowing the packaging of pills (i.e. white and green balls). This one is made up of a conveyor and four stations of treatment allowing the filling of pills into tubes (figure 2):

- Station 1: distribution of white pills by counting,

- Station 2: installation of a cap on the large tube,

- Station 3: distribution of green pills by counting,

- Station 4: installation of a cap on the small tube and/or evacuation of the tube in a box.

The objective was to propose to the students a project within the framework of a 30 hours practical work (10 meetings * 3 hours) dedicated to the realization of an automation project, from specifications to realizations (PLC programs and SCADA applications) (Riera et al., 2005). The students must apply their courses about PLC programming, industrial communication (Ethernet, OPC...) and SCADA (Supervisory Control and Data Acquisition) applications. In order to motivate the students, and to impose temporal pressure, a partnership with a teacher of 5-year-old children has been carried out. Thirty children had to come to the University in the late of October to use the machine by the mean of an Internet navigator. Voluntarily, the contractual specifications transmitted to the students were reduced and concerned the following points:

- Choice of the level of automation (Sheridan, 1997), (Parasuraman and al., 2000), in adequacy with the pedagogical objectives of the children's teacher,

- To make safe the access to the "Productis" machines and to limit children's activities.
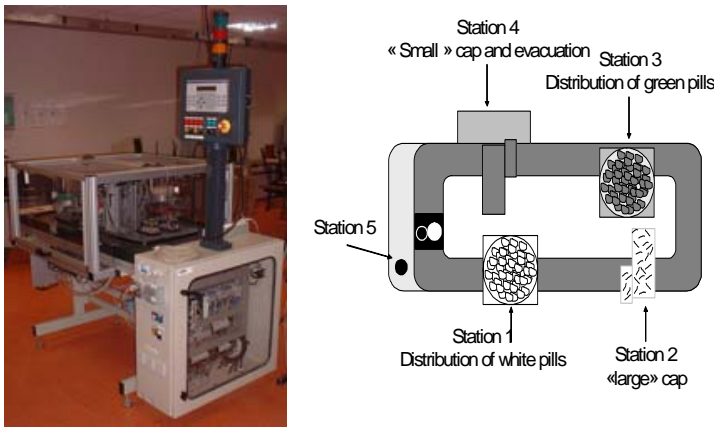

Figure 2: The "Productis" machine

The students very quickly understood the need for children to script the activity as a story. They had to define and identify the requirements of a 5-year-old customer! At this age, the activity must be game or story oriented. The proposed scenario consisted to propose to the children to manufacture medicine to look after sick animals (cows, bear, and crocodiles). The teacher worked on this topic with children before coming to use the machine. The controller was carried out according to the level of automation defined by the teacher. Figure 3 presents the technical automation architecture performed.

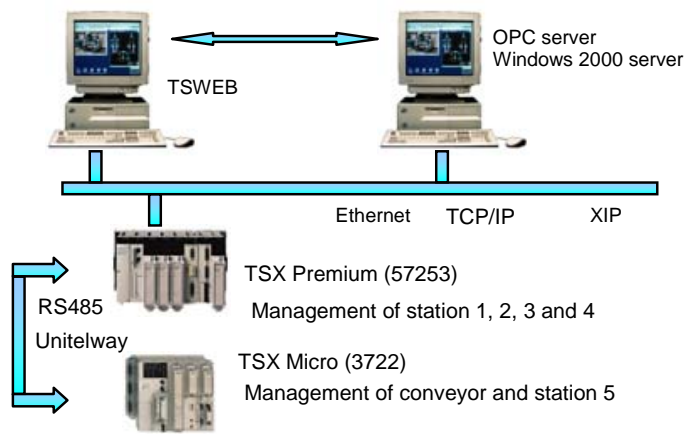

Figure 3 Automation structure

The obtained results were excellent. The children (and adults accompanying) were very impressed by the experiment. The children were completely filled with wonder by the machine and its piloting by means of a computer. The children had few difficulties to use the HMI (Human-Machine Interface) and perfectly understood the effects of causality between the "click" on an "object" of the HMI and its consequences on the machine. The teacher found the experiment pedagogically very rich. The fact of going to the laboratories of "the University” was much appreciated.

This kind of project is goal oriented, more realistic and more professional. Too often in higher education, projects do not have a purpose other than teaching. The students are then "motivated" or "constrained" by the note. Moreover, the aspects of project management and "finished product", present in the industrial life, have been taken into account by the students. From a technical point of view, as seen, these projects enable to apply many fields of the automatism. This experiment was rich for everybody 
(students and children). This project was a nice way to have the world of the E.E.A. (Electronic, Electric engineering, Automatic) discovered by children and maybe vocations were caused. In addition, the event was followed by the local press, giving a nice picture of our technical courses.

Within the framework of this project, the Internet use was local. Indeed, even if the teacher carried out some tests of HMI via the WEB, children came to University to monitor the machine. The following part of the article carries out the possibilities of the Communication and Information Technologies and Internet for DES teaching.

\section{INTERNET AND D.E.S. TEACHING}

\subsection{Various possible tools}

Clearly, the Communication and Information Technologies can be used within the framework of the training "to open" the practical work classrooms to the world. Hence, it becomes possible for everybody to get an access to hardware (PLC and plant) and software that they can not usually use at home. The idea, we have started to manage, is to create a practical work distributed classroom allowing connection to resources being physically to different places. As an example, the University of Reims Champagne Ardenne (URCA) is located in three different sites (Reims, Troyes, CharlevilleMézières), far from each other, and approximately 5 practical work classrooms with different PLC, specific to different technical departments (UFR Sciences, IUT, engineer's school...). If in each classroom, one PLC is available through the WEB, we would get a $6^{\text {th }}$ distributed classroom with 5 PLC. This approach can be extended to several universities in partnership. It is the case with URCA and Polytech'Tours (http://auto.polytech.univ-tours/mv).

The remote PLC use (figure 4) can be used in selftraining, or in classical practical work, in group supervised by a teacher. As we have seen, these two applications raise several teaching (controller program validation) and technical questions (choice of the technology). Indeed, by this approach, we can give access to resources to students without them inevitably having the requisites to use them. However, we consider that using tools via Internet is complementary to the practical work with a teacher. The student can in self-training, to finish a subject or to prepare another. In addition, it is complementary to the provision of traditional Internet resources like "courses and corrected exercises". It can be completely integrated in an e-learning platform. Hence, students can get a technical know-how by the mean of specialized software packages (PL7-pro for example for the programming of Schneider PLC).

The student, to evaluate the performance of his/her programming must test it on a real or simulated plant. The practical work distributed classroom seems to us a very interesting idea. For safety reasons, we directed our work towards the use of real control part connected to a simulated plant. This work is the subject of the following paragraph where different technical architectures are proposed.

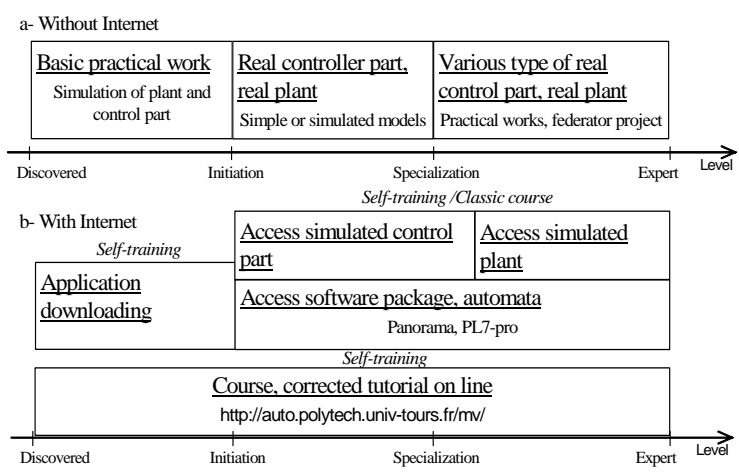

Figure 4: Internet and D.E.S. teaching

\subsection{Remote control part and simulation of plant via Internet}

Within the framework of a regional project (Champagne-Ardenne), we have performed a study (Riera and Gellot, 2005) on the different technical solutions giving remote access to the PLC connected to simulated plant, and respecting the following specifications :

- Simple connection via Internet,

- Secure access to PLC,

- Facility of use of the plant simulation.

One simple solution is to authorize the student to connect to a server via the service "remote desktop" and "Terminal Service by the Web" (TSWEB) (Noterman et al., 2002). This system allows each user connected to carry out programs directly on the server rather than on its own station. Actually, the applications are carried out on the server and are sent to the customer station. All data processing are performed by the server. The client station is used like a simple graphic interface, whereas all calculations are made on the server. With this tool, only the server station has to be maintained. The Remote Desktop functionality is native in Windows XP PRO, Windows 2000 server and Windows 2003 server. Another very interesting point is that the client can be a MAC or a PC with a Linux kernel. Hence, specific software running only on Microsoft operating system can be used by other systems.

The following technical problem is connection between PLC and a simulated plant. We studied three solutions to giving their respective advantages and disadvantages according to four criteria (the generics, the simplicity of implementation, the use and ergonomics for student, synchronization between control part and plant):

1. Simulation and HMI are both in the PLC ((solution 1),

2. Simulation and HMI are both in the server(solution 2),

3. Simulation is in PLC and HMI is in the server (solution 3) (Chemla and al., 2005).

Table 1 presents the advantages and the disadvantages of each technical solution. We have in our case selected the solution 1 when it is possible. 


\begin{tabular}{|c|c|c|c|c|}
\hline & Generic & Simplicity of implementation & Use and ergonomics & Synchronization \\
\hline Solution1 & $\begin{array}{l}- \\
\text { all the programming } \\
\text { software of PLC do not } \\
\text { integrate a SCADA }\end{array}$ & $\begin{array}{c}+ \\
\text { only one software for the } \\
\text { PLC programming, plant } \\
\text { simulation and } \mathrm{HMI}\end{array}$ & $\begin{array}{c}+ \\
\text { Programming PLC software } \\
\text { have reduced SCADA } \\
\text { functions }\end{array}$ & $\begin{array}{c}++ \\
\text { perfect }\end{array}$ \\
\hline Solution2 & $\begin{array}{c}++ \\
\text { with OPC servers and } \\
\text { SCADA }\end{array}$ & $\begin{array}{c}-- \\
\text { several software have to be } \\
\text { parameterized and } \\
\text { communication requirement } \\
\text { between the server and the } \\
\text { PLC }\end{array}$ & $\begin{array}{c}\mathbf{+ +} \\
\text { graphic objects and many } \\
\text { animations are possible in } \\
\text { SCADA systems }\end{array}$ & $\begin{array}{l}\text { important risk of information } \\
\text { loss, difficult synchronization } \\
\text { between plant simulator and } \\
\text { PLC }\end{array}$ \\
\hline Solution3 & $\stackrel{++}{\text { idem solution } 2}$ & idem solution 2 & $\stackrel{++}{\text { idem solution } 2}$ & $\begin{array}{l}+ \\
\text { The server is just used for } \\
\text { the display, no } \\
\text { synchronization problem }\end{array}$ \\
\hline
\end{tabular}

\section{CONTROLLER CHECKING}

In this article, we highlighted several times the need to testing partially the controller. Indeed, on a real plant, it is obviousness. In the case of using a simulated plant in self-training, the controller checking must be seen like a mean for the student to understand his errors. It is thus a tool able to explain and cooperate in a certain way with the student. It is for example possible to use the checking results to generate operation scenarios. The last part of the article tackles the problem of the checking and gives some exploratory tracks.

We propose to install a tool "off line" guaranteeing that the controller proposed by the student is "valid" according to criteria's fixed by the teacher. For that, work of (Carré and al., 2002) on the controller synthesis starting from a controller model expressed in the Grafcet form will be exploited in a different way. For that, we are interested in the work undertaken in (Marangé and al., 2006) on the controller synthesis, where it is shown that it is possible to use the synthesis approach in a diverted way to make verification. The synthesis step is articulated in three stages (figure 5).

The first stage is a modelling stage of a deterministic and reactivates controller (SSA) starting from the Grafcet model of the controller according to the Roussel's algorithm (Roussel, 1996). In this stage, we have also the generation of the supervisor $\mathrm{S}$ which describes the broadest acceptable behaviour commandable process compared to the constraints specified according to the Kumar's (Kumar, 1991) synthesis algorithm.

The second stage is the controller generation, which consists in filtering the Grafcet actions when they are not acceptable by the supervisor $\mathrm{S}$ and to withdraw the blocking evolutions.

The last stage relates to the execution of the established controller and animation of the original Grafcet with visualization of the corrections made to this one.

Initially, the synthesis step of suggested controller can be used in controller verification, like a help with the teacher. We thus place ourselves in the case of real plant use. Within this framework, that consists in inserting a system in the design loop between the student and the teacher to guarantee that the controller is "valid" according to criteria's fixed by the teacher.

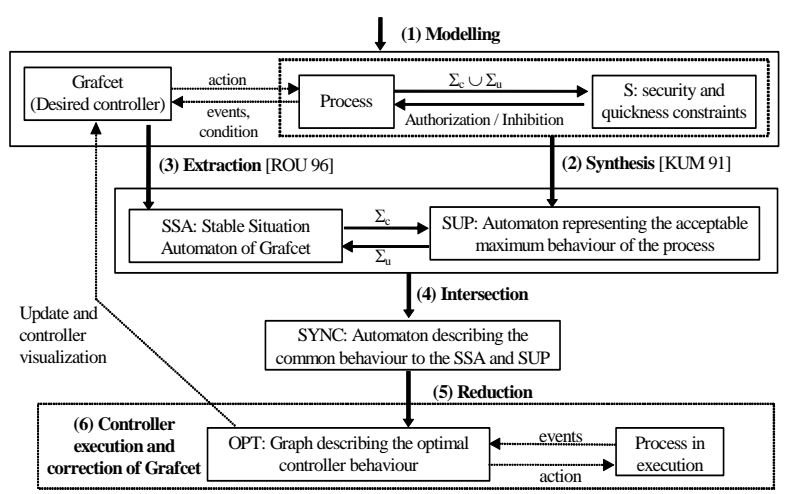

Figure 5: Synthesis approach starting from Grafcet specifications

We then seek to verify if Grafcet proposed by student is correct with respect to the operation constraints of plant specified by the teacher. For this proposal, it is necessary to take into account the following conditions:

- The design of the operation constraints is the responsibility of the teacher who has the knowledge of the schedule of conditions. The teacher is thus free to define the constraints which he/she wants. Those can be related to security aspects or functional aspects linked to specifications,

- The design of the controller in the Grafcet form is under the responsibility of student according to the schedule of conditions provided by the teacher. No particular constraint is imposed to him for this activity except the respect of the definition of the model (IEC, 2002),

- In this first approach, it is to the teacher to use the results coming from the synthesis to transmit them to students (not compliance with safety requirements, not respect of the contractual condition...).

It is thus a question of exploiting information resulting from the controller synthesis, in a completely transparent way for the teacher, to detect the constraints defined by the teacher which were violated by the order of learning (figure 6).

Two cases can then occur at the intersection operation end:

- The controller respects the constraints then the student is authorized to transfer his Grafcet to the PLC. Hence, in full safety, the teacher can be sure that there is no risk for the operative material,

- The delivered controller by student is not correct. The teacher, after analysis of the situation 
informs him about reasons. So, the student has to propose and perform controller corrections.

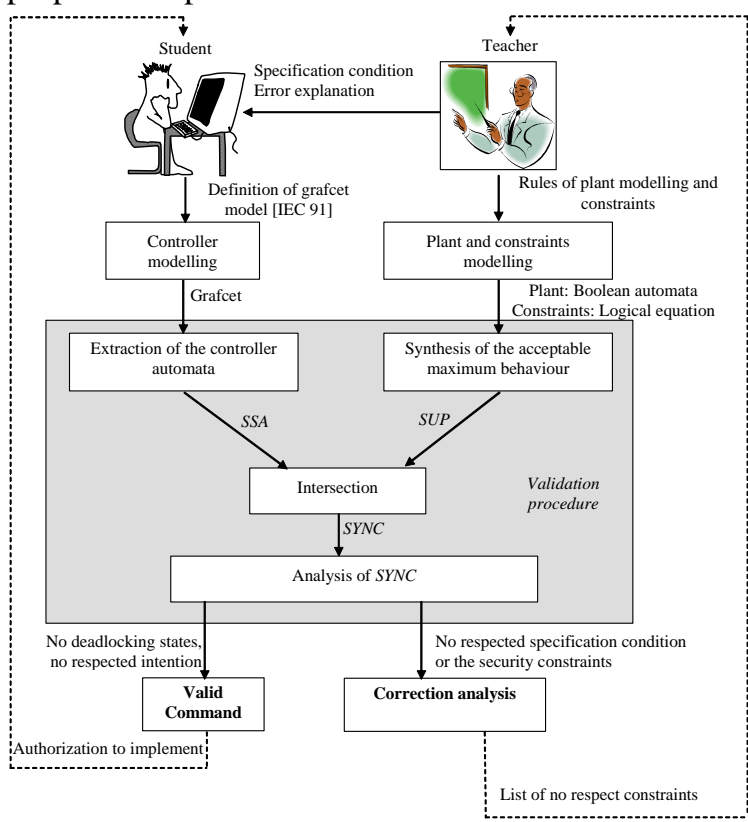

Figure 6: Principle of the controller verification

Within the framework of a use in self-training with a simulated plant, it is necessary to develop a module able to analyze the intersection automata results and to propose a mean to represent and to display the no respected constraints. That can be done by the display of the response behaviour of the simulated plant to a judicious scenario, or by an original representation of the constraints. This work is our future research object.

\section{CONCLUSION}

This article deals with the possibility of Internet and advanced technologies for D.E.S teaching. The needs are very dependent on the objectives of the training. However, from discovery to specialization, Internet offers interesting possibilities. In this paper, we are interested in the remote control of real or simulated PLC connected to real or simulated plant. In this article, several possibilities were presented. The use of simulated plant connected to PLC has been more particularly studied. Several technical architectures have been proposed and tested in order to develop the concept of practical work distributed classroom. Lastly, we have shown as well within the framework of the use of real plant with a teacher as of the use in self-training of simulated plant, the problem of the controller verification is posed. Some exploratory tracks of research were discussed.

\section{ACKNOWLEDGMENTS}

We gratefully acknowledge the Champagne Ardenne region for its support in these projects.

\section{REFERENCE}

Carré Menertrier V., Zaytoon J., "Grafcet: behavioural issues and control synthesis", European Journal Control, vol.8, n4, p375401, International journal of production research, 2002
Chemla J.P., Riera B., Gellot F., Kouame D., "Simulation de partie opératives temps réel pour l'enseignement de l'automatique”, CETSIS'05, Nancy, France, 25-27 octobre 2005

Hsieh S. J., "Work in Progress - Integration technology for E-Diagnosis of automated manufacturing system", $34^{\text {th }}$ ASEE/IEEE Frontiers in education conference, october 2023, Savannah, GA, 2004

International Electrotechnical Commission, "Preparation of function charts for control systems”. Publication 848, 2002

Kumar R., "Supervisory synthesis techniques for discrete event dynamical systems", Thesis for PH. D. Degree, University of Texas, 1991

Lottin J., Morteau S., "Le pendule inverse: un système hybride?”, CETSIS'05, Nancy, France, 25-27 octobre 2005

Lunt B.M., Helps H.G., Carter P., Red E., "Systems and automation education through Web-based labs”, ICEE 2000, Taiwan, august 14-16, 2000

Marangé P., Tajer A., Gellot F., Carré V., "Synthesis of supervised controller based on Boolean constraint and Boolean automata", INCOM'06, St Etienne, France, mai 2006

Metzger M., “Agent-based virtual control systems for DCS education via Internet”, S3b_4, IFAC Workshop IBCE'04, Grenoble, France, september 5-7 2004

Noterman D., Coquard P., Guillemot M., Louoil G., "Plate-forme e-learning pour l'enseignement de l'automatique des systèmes à événements discrets", EDUTICE'02, Lyon, France, novembre 2002

Parasuraman, R., Sheridan, T.B., Wickens, C.D. "Model for types and levels of human interaction with automation”, IEEE Transactions on SMC Part A: Systems and Humans, 30-3, pp 286-297, 2000.

Riera B., Gellot F., Marangé P., Chemla J-P., Sayed Mouchawed M., "Un projet original en commande et supervision des systèmes automatisés : Des enfants de 5ans au secours d'animaux malades! ”, CETSIS'05, Nancy, France, 25-27 octobre 2005

Riera B., Martel G., Angué J-C., "La simulation : outil pédagogique pour l'enseignement de l'automatique dans la formation professionnalisée ", Sciences et techniques éducatives, vol.6, p37-60, n²1/1999

Roussel J-M., Lesage J.J., "Validation and verification of Grafcet using state machine”, Proceedings of IMACS-IEEE "CESA'96" pp. 758-764, Lille, France, 9-12 July 1996

Schneider Electric, Productis, Notice technique. I, I6S6F, MD1AD901, juin 2001

Sheridan, T.B. "Supervisory Control, Handbook of Human Factors and Ergonomics" (second edition), edited by Gavriel Salvendy, Chapter 58, pp.1295- 1327, 1997.

Tauvel A., Flety E., "Régulateur de vitesse pour MCC : Choix d'un contrôle à distance”, CETSIS’05, Nancy, France, 25-27 octobre 2005 